\title{
A survey on existing challenges of BSC implementation for performance measurement
}

\author{
Behdad Gitinejad $^{\mathrm{a}^{*}}$ and Mohammad Ali Keramati ${ }^{\mathrm{b}}$
}

${ }^{a}$ M.S Candidate in Industrial engineering, Islamic Azad University of ARAK, Iran

${ }^{b}$ Assistant Professor, Islamic Azad University of ARAK, Iran

CHRONICLE ABSTRACT

Article history:

Received July 28, 2013

Received in revised format

20 November 2013

Accepted 4 January 2014

Available online

February 142014

Keywords:

Balanced scorecard

BSC

Strategy management

Performance management

Governmental sector

\begin{abstract}
The balanced scorecard (BSC) is a strategic oriented tool used comprehensively in profit and nonprofit organizations all over the world to synchronize routine processes of organizations to the mission and strategy, improve inner and outter communications, control organization performance toward strategic targets. BSC has emerged from a simple performance measurement framework to a comprehensive strategic management system. It changes an organization's strategic plan from a passive document to an active guideline for the organization on a daily basis and provides a helpful assistance that not only enables performance measurements, but also helps planners identify what should be accomplished and measured. This study focuses on how BSC is adopted as a tool for measuring effectiveness of strategy implementation in these organizations. This study adapts the BSC as a powerful tool for reaching an organization's performance in four significant areas: Financial perspective, Customer-Market perspective, Internal Processes perspective and Learning \& Growth perspective. The results suggest that governmental organizations are somehow successful in achieving their objectives in various degrees.
\end{abstract}

\section{Introduction}

Balanced scorecard (BSC) divides strategies into significant components called strategic objectives and it contributes for the improvement of actions linked in a value creation process in four distinct perspectives including learning and growth, internal business, financial and customer. Generally, improving performance in terms of Learning \& Growth perspective enables organizations to improve their Internal Process perspective Objectives, which in turn helps them create desirable results in the Customer and Financial perspectives shown in Fig 1. Each strategic objective has one or more associated Strategic Performance Measures and BSC contains Strategic Initiatives to reach targeted levels of organizational performance. Building a comprehensive strategy is a hard problem for any

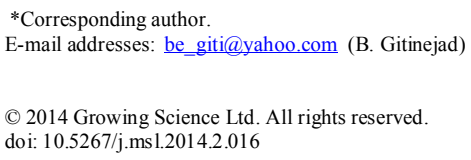


strategic team to make that strategy successful. Some important factors can influence on the process by making change on strategic plans for better access to strategic targets, effectively. Therefore, it is not surprising that, after a comprehensive strategy has been created, some challenges arise during the subsequent implementation process. The best-shaped strategies may be not successful in formulating the best performance for the organization if they are not broadly studied (Noble, 1999). Allio, (2005) performed a survey among 196 senior operating executives in 2004 and reported that only $47 \%$ of firms were unsuccessful at executing strategic initiatives. Some factors can influence the success of strategy implementation, ranging from the people to the mechanisms in co-ordination and control. Setback in implementation of strategies may also result from lack of cross-functional expertise and efforts on the part of organizational leadership and staffs hence they may fail to address the interdependent issues, more effectively.

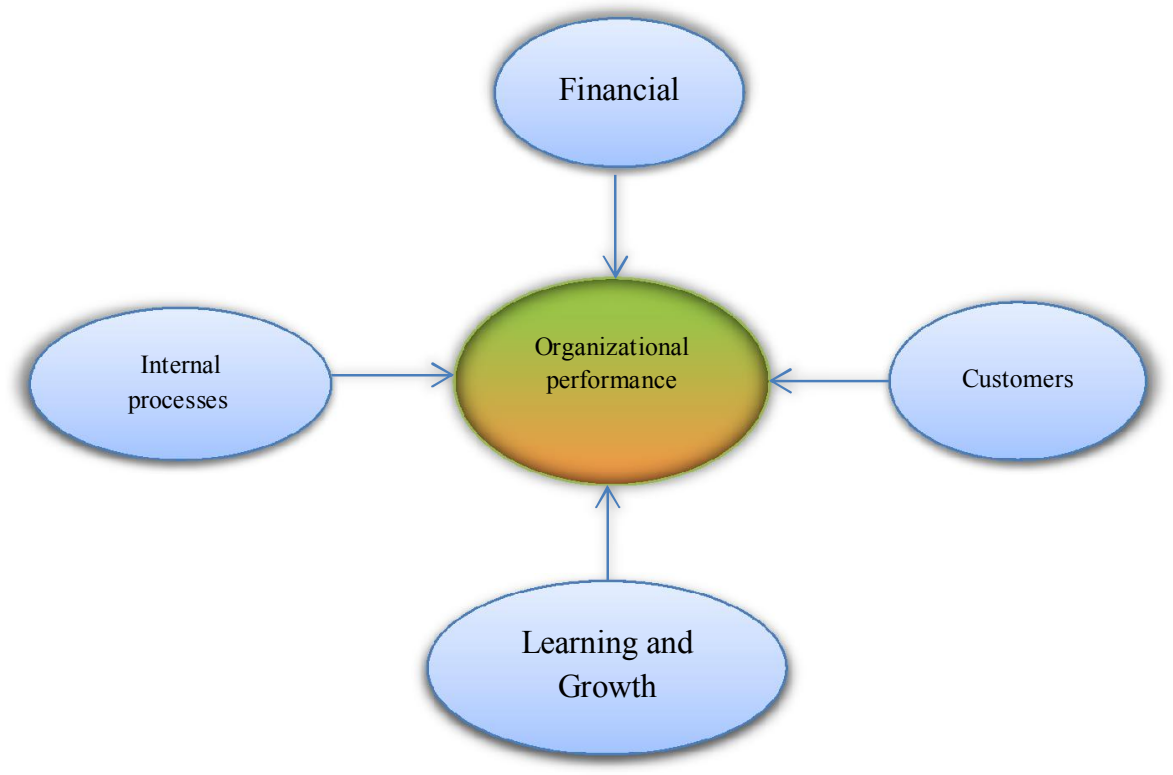

Fig. 1. The Four Perspectives in BSC

Lack of systems and purposeful actions in incorporating different organizational variables including organizational arrangements, processes, social factors individual behavior and technology could lead to implementation failure. Other factors including resistance to change, insufficient strategic motivation and inability to adapt to rapidly changing environment will all lead to strategy implementation failure (Priest \& Gass, 1997).

Making availability for public services and increasing the quality of services are important challenges for efficiency and effectiveness of the public sector (Newman, 2000). The implementation of BSC in the public sector can be of great catastrophe because of the particular characteristics of such organizations (Kaplan \& Norton, 2008). However, there are numerous difficulties in performance measurement in public sector (Wisniewski \& Ólafsson, 2004). The public sector entities need to analyze the correlation of the BSC perspectives and need to be adapted to fit the nature of public entities (Wisniewski \& Ólafsson, 2004). Wilson et al. (2003) examined the use of BSC in public organizations in various countries and concluded that the BSC approach had proven to be a wellaccepted management practice within public sector as a useful tool for developing, discussing and selecting the most relevant decision-taking and performance indicators in public sectors. BSC constitutes an important management tool to facilitate this management style in governmental organizations (Ho \& Chan, 2002; Wisniewski \& Ólafsson, 2004; Chan, 2004). With respect to this, Wisniewski and Ólafsson, (2004) stated six significant aspects for the development of BSC as follows: 
- The process is as important as the product;

- Strategy mapping is an essential element for successful implementation of BSC;

- Re-labeling to maintain their relevance;

- Resources allocation to frontline service delivery rather than back-office activities;

- A visible and direct benefit to those staff who will develop and use the scorecards;

- Use of strategy maps to join up scorecards across different parts of organization.

The adoption and deployment of BSC to performance management has been a critical problem for a long time, but studies from the manufacturing and industrial sectors appears to far out-weigh that from public service environments (Radnor \& Lovell, 2003; Eskilden et al., 2004; Moxham \& Boaden, 2007). In the governmental sectors, the measures of a BSC are not simply concentrated on the private sector but the ultimate goal is financial, and the "learning and growth perspective" helps a company in improving its processes that in turn influences on the "customer perspective" results, which leads to improved financial performance. As for the public organization, instead, the "learning and growth perspective" is equally important with respect to the "financial perspective" and the final objective refers to the "customer's perspective". Moullin (2004) acknowledges that even if the BSC model has been used in the public sector environments, there are still difficulties associated in particular with its implementation in this sector.

\section{The proposed Study}

The proposed study of this paper applies BSC techniques on Iranian Telecommunication organization. The study selects a sample from the heads of all the departments in the organization mainly sales and marketing, services, customer relationship management, accounting, and human resources management. Personal interviews with the heads were conducted using an interview guide and conceptual content analysis were used to make inferences. Out of the 30 sampled heads of departments, 24 were available for interview with response rate of $80 \%$. The respondents indicated that the annual performance measurement process followed the company. The organization set goals at the beginning of the financial year based on overall targets. The performance appraisal is top down, obligatory and linked to the corporate strategic goals. $54.3 \%$ of the respondents had over 3 years of experience. The rest had less than three years of job experience with this organization. However, they all are believed to have some good insight about the existing issues associated with the firm. Fig. 1 shows the use of BSC for performance measurement.

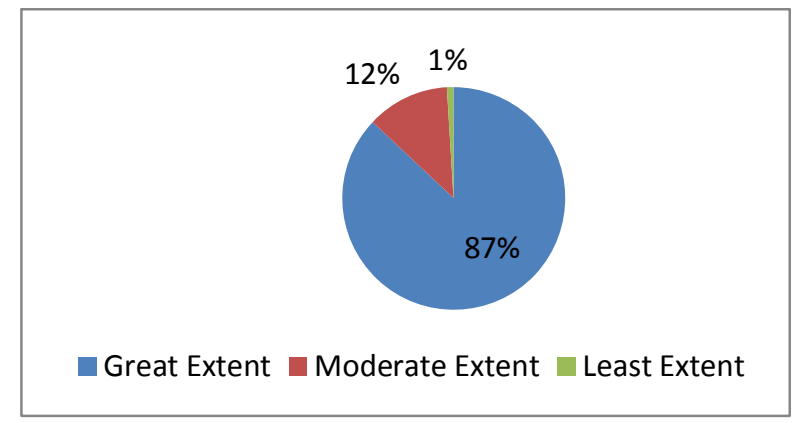

Fig. 1. Use of the balanced scorecard in performance measurement

According to Fig. 1, 87\% of the respondents indicated that the balance score card was in use to a great extent, $12 \%$ agreed that at this organization the balanced score card was in moderate use while $1 \%$ were not very sure that the measures in place to measure performance were linked to the balanced score card. 
The respondents were asked to state the extent of usage of financial, customer satisfaction, Innovation and change as performance measures.

Table 1

Usage of financial, customer satisfaction, innovation and change as performance measures

\begin{tabular}{lcccc}
\hline Performance perspective & Not at all & Least & Moderate & Great extent \\
\hline Financial performance & $0 \%$ & $0 \%$ & $0 \%$ & $100 \%$ \\
Customer satisfaction & $0 \%$ & $0 \%$ & $14.30 \%$ & $85.70 \%$ \\
Innovation and change & $0 \%$ & $0 \%$ & $28.60 \%$ & $71.40 \%$ \\
\hline
\end{tabular}

According to the results of Table 1, 100\% of the respondents agreed that financial measures were in use to a great extent, while customer satisfaction and innovation and change were in use at only $85.7 \%$ and $71.4 \%$ respectively to a great extent. In addition, they were used in moderate extent only at $14.3 \%$ and $28.6 \%$, respectively. Table 2 shows the results of our survey in terms of value, quality and use of performance measures in support of BSC.

Table 2

Value, quality and use of Performance measures in support of BSC

\begin{tabular}{lcccc}
\hline Performance perspective & Not at all & Least & Moderate & Great extent \\
\hline Measures are clearly defined in each performance area. & $0 \%$ & $0 \%$ & $0 \%$ & $100 \%$ \\
Information from employees is highly valued. & $0 \%$ & $0 \%$ & $14.30 \%$ & $85.70 \%$ \\
Measures are adopted for internal and external users. & $0 \%$ & $0 \%$ & $57.10 \%$ & $42.90 \%$ \\
Measures are used for management and mentoring. & $0 \%$ & $0 \%$ & $42.90 \%$ & $57.10 \%$ \\
Measures are used for strategic planning. & $0 \%$ & $0 \%$ & $14.30 \%$ & $85.70 \%$ \\
Measures are used for regular management reviews. & $0 \%$ & $0 \%$ & $42.90 \%$ & $57.10 \%$ \\
Measures are used for resource allocation. & $0 \%$ & $0 \%$ & $85.70 \%$ & $14.30 \%$ \\
Measures are used to drive change. & $0 \%$ & $0 \%$ & $57.10 \%$ & $42.90 \%$ \\
Measures used are linked to compensation. & $0 \%$ & $0 \%$ & $0.00 \%$ & $100.00 \%$ \\
\hline
\end{tabular}

According to the results of Table 2,100\% of the respondents indicated that performance measures were completely defined in each performance area. In addition, $85.7 \%$ of the participants believed information from employees was highly valued and measures used for strategic planning. The respondents were asked to what extent they agreed with the following statements on the use of balanced score card.

Table 3

Application of balanced score card

\begin{tabular}{|c|c|c|c|c|}
\hline BSC applications & Not at all & Least & Moderate & Great extent \\
\hline Balanced score card is a fad & $14.30 \%$ & $71.40 \%$ & $0.00 \%$ & $14.30 \%$ \\
\hline Balanced score card is an employee empowerment system & $0.00 \%$ & $0.00 \%$ & $71.40 \%$ & $28.60 \%$ \\
\hline $\begin{array}{l}\text { Balanced score card is an organization`s strategic management } \\
\text { system }\end{array}$ & $0.00 \%$ & $0.00 \%$ & $71.40 \%$ & $28.60 \%$ \\
\hline $\begin{array}{l}\text { Balanced score card is an adhoc collection of financial and } \\
\text { nonfinancial measures }\end{array}$ & $0.00 \%$ & $57.10 \%$ & $28.60 \%$ & $14.30 \%$ \\
\hline $\begin{array}{l}\text { Balanced score card complements the financial measures of past } \\
\text { performance with operational measures that drive future growth } \\
\text { and performance }\end{array}$ & $0.00 \%$ & $0.00 \%$ & $0.00 \%$ & $100.00 \%$ \\
\hline $\begin{array}{l}\text { The benefits will outweigh the costs if } \\
\text { balanced score card was implemented } \\
\text { fully }\end{array}$ & $0.00 \%$ & $0.00 \%$ & $0.00 \%$ & $100.00 \%$ \\
\hline
\end{tabular}

Based on the results of Table 3, we observe that $100 \%$ of the respondents believed that, largely, BSC complements of the financial measures of past performance with operational measures that drive future growth and performance and that the benefits will outweigh the costs if BSC was implemented fully. Only $14.3 \%$ indicated that the BSC was a fad. 
Table 4

Challenges of using balanced scorecard to measure performance Challenge

\begin{tabular}{lcccc}
\hline Challenge & Not at all & Least & Moderate & Great extent \\
\hline Managements are too busy to solve and to implement short-term goals. & $0.00 \%$ & $42.90 \%$ & $14.30 \%$ & $42.90 \%$ \\
\hline Inadequate top management support & $0.00 \%$ & $14.30 \%$ & $85.70 \%$ & $0.00 \%$ \\
\hline Lack of highly developed information system to support balanced score card & $0.00 \%$ & $28.60 \%$ & $14.30 \%$ & $57.10 \%$ \\
\hline Lack of linkage of balanced score card to employee reward & $0.00 \%$ & $42.90 \%$ & $57.10 \%$ & $0.00 \%$ \\
Balanced score card is time consuming to develop & $0.00 \%$ & $0.00 \%$ & $42.90 \%$ & $57.10 \%$ \\
\hline Lack of skills and know how in developing and implementing balanced score card & $0.00 \%$ & $0.00 \%$ & $57.10 \%$ & $42.90 \%$ \\
\hline Organizational politics & $0.00 \%$ & $14.30 \%$ & $57.10 \%$ & $28.60 \%$ \\
\hline Change management strategies & $0.00 \%$ & $14.30 \%$ & $57.10 \%$ & $28.60 \%$ \\
\hline Revenue constraints & $0.00 \%$ & $0.00 \%$ & $85.7 \%$ & $14.3 \%$ \\
\hline Implementation of balanced score card is cost prohibitive & $0.00 \%$ & $0.00 \%$ & $0.00 \%$ & $100 \%$ \\
\hline Difficult to evaluate the importance of various measures & $0.00 \%$ & $28.6 \%$ & $57.1 \%$ & $14.3 \%$ \\
\hline Difficult to define and measure outcome measures & $0.00 \%$ & $0.00 \%$ & $100 \%$ & $0.00 \%$ \\
\hline
\end{tabular}

As we can observe from the results of Table 4, more than half of the participants in our survey believed that there were not sufficient information system to support BSC and it is a time consuming to develop a good model. In addition, nearly half of the participants stated that people need to have more skills to develop BSC and management teams were too busy to apply BSC for short-term objectives.

\section{Conclusion}

The productivity of strategic performance depends on the quality that the process is managed. Once the organization has set up the strategies to secure the resources and defined a timeframe to attain the targets, the employees must control the progress of the project and highlight the milestones. BSC plays the primary key role in provision of investigating in their areas of concentration. BSC receives significant amount of information from the process of strategy implementation in terms of calculating the financial, customer service, internal process operations and learning and growth perspectives to measure the effectiveness of strategy implementation. Most of the respondents indicated that we needed to improve on the effectiveness of strategy implementation in the governmental organizations. Governmental sectors use BSC primarily for strategy implementation and performance management tool in terms of financial, customer, innovation. The results of our survey have shown that many managers may be unwilling to apply BSC for short-term objectives solely because they are wonderfully busy with their daily activities. Therefore, it is necessary to provide sufficient awareness about the advantages of BSC implementation in early stage. The study further stated that the benefits of BSC outweigh the costs if implemented completely, efficiently and effectively and that it complements the financial measures of past strategic data with operational indicators that drive future performance and improvement.

\section{References}

Allio, M. K. (2005). A short, practical guide to implementing strategy. Journal of Business Strategy, 26(4), 12-21.

Chan, Y. C. L. (2004). Performance measurement and adoption of balanced scorecards: a survey of municipal governments in the USA and Canada. International Journal of Public Sector Management, 17(3), 204-221.

Eskildsen, J. K., Kristensen, K., \& Juhl, H. J. (2004). Private versus public sector excellence. The TQM Magazine, 16(1), 50-56.

Ho, S. J. K., \& Chan, Y. C. L. (2002). Performance measurement and the implementation of balanced scorecards in municipal governments. Journal of Government Financial Management, 51(4), 8-19.

Kaplan, R. S., \& Norton, D.P. (2008). The Execution Premium: Linking Strategy to Operations for Competitive Advantage. Boston: HBS Press. 
Newman, J. (2000). Beyond the new public management? Modernizing public services. New managerialism, new welfare, 45-61.

Moullin, M. (2004). Using the public sector scorecard in health and social care. In Proceedings of the performance measurement association conference, Edinburgh. Cambridge University Press.

Moxham, C., \& Boaden, R. (2007). The impact of performance measurement in the voluntary sector: Identification of contextual and processual factors. International Journal of Operations \& Production Management, 27(8), 826-845.

Noble, C. H. (1999). The eclectic roots of strategy implementation research. Journal of Business Research, 45(2), 119-134.

Priest, S., \& Gass, M. A. (1997). Effective Leadership in Adventure Programming. Human Kinetics PO Box 5076, Champaign, IL 61825-5076.

Radnor, Z., \& Lovell, B. (2003). Success factors for implementation of the balanced scorecard in a NHS multi-agency setting. International Journal of Health Care Quality Assurance, 16(2), 99108.

Wilson, C., Hagarty, D., \& Gauthier, J. (2004). Results using the balanced scorecard in the public sector. Journal of Corporate Real Estate, 6(1), 53-64.

Wisniewski, M., \& Ólafsson, S. (2004). Developing balanced scorecards in local authorities: a comparison of experience. International Journal of Productivity and Performance Management, 53(7), 602-610. 